\title{
Molecular epidemiology of mtDNA mutations in 903 Chinese families suspected with Leber hereditary optic neuropathy
}

\author{
Xiaoyun Jia $\cdot$ Shiqiang Li $\cdot$ Xueshan Xiao • \\ Xiangming Guo $\cdot$ Qingjiong Zhang
}

Received: 15 May 2006/ Accepted: 14 June 2006/ Published online: 14 September 2006

(C) The Japan Society of Human Genetics and Springer-Verlag 2006

\begin{abstract}
We report the molecular epidemiology of three primary mutations in mitochondrial DNA (mtDNA) responsible for Leber hereditary optic neuropathy (LHON) based on analysis of probands suspected with LHON from 903 Chinese families. Most of them had optic neuropathy of unknown cause, and only 128 had a family history of optic neuropathy. Mutations in the mtDNA were detected in 346 probands. Of the 346 cases, 340 were homoplasmic and only six were heteroplasmic; 284 were male and 62 were female; 120 had a family history and 226 were sporadic. G11778A, T14484C and G3460A mutations were detected in $312(90.2 \%)$, 30, and four families, respectively. The majority $(226 / 346,65.3 \%)$ of all LHON cases in Chinese are sporadic. These 226 probands $(29.2 \%)$ were identified from 775 probands with sporadic optic neuropathy. Affected male-to-female ratio was 4.6:1 for all probands but was 2.2:1 for family members. Average age at onset was 18.5 years, ranging from 4.5 to 47 years old.
\end{abstract}

Keywords Leber hereditary optic neuropathy • mtDNA mutation $\cdot$ Epidemiology $\cdot$ Sporadic $\cdot$ Chinese

X. Jia $\cdot \mathrm{S}$. Li $\cdot$ X. Xiao $\cdot$ X. Guo $\cdot$ Q. Zhang

State Key Laboratory of Ophthalmology,

Zhongshan Ophthalmic Center, Sun Yat-sen University,

Guangzhou 510060, China

Q. Zhang $(\bowtie)$

Ophthalmic Genetic and Molecular Biology,

Eye Research Institute, Zhongshan Ophthalmic Center,

Sun Yat-sen University, 54 Xianlie Road,

Guangzhou 510060, China

e-mail: qingjiongzhang@yahoo.com

\section{Introduction}

Optic neuropathy is a common ocular disease causing blindness. Genetic defects play an important role in the etiology of the disease, especially in familial cases (Votruba 2004). Hereditary optic neuropathy has been reported to be transmitted as autosomal dominant (OPA1, 3q28-q29, OMIM165500; OPA3, 19q13.2q13.3, OMIM 606580; OPA4, 18q12.2-q12.3, OMIM605293), autosomal recessive (ROA1 or OPA5, 8q, OMIM 258500), X-linked recessive (OPA2, Xp11.4-p11.21, OMIM311050; Jensen syndrome, Xq22, OMIM311150), and maternal (OMIM535000, LHON) traits. Mutations in OPA1 (OMIM605290), OPA3 (OMIM 606580), TIMM8A (OMIM 300356) and mitochondrial DNA (mtDNA) genes (MTND1, OMIM516000; MTND4, OMIM516003; MTND6, OMIM516006) have been reported to be responsible for autosomal dominant, $\mathrm{X}$-linked recessive and maternal inherited optic neuropathy.

Leber hereditary optic neuropathy (LHON) is the first maternally inherited disease recognized and is the first hereditary disease associated with mtDNA mutation. It is the common cause of subacute vision loss in young adults. Several mutations in the mitochondrial genome have been reported to be responsible for LHON. Such mutations in most cases, as high as $95 \%$, occurred at mtDNA nt11778, nt14484 and nt3460 (Huoponen et al. 1991; Johns et al. 1992; Mackey et al. 1996; Man et al. 2003; Mashima et al. 1998; Wallace et al. 1988). The spectrum of these three common mutations varied in different ethnic groups (Man et al. 2003; Marotta et al. 2004; Mashima et al. 1998; Nishioka et al. 2003; Phasukkijwatana et al. 2006; Shanske and Wong 2004; Taylor et al. 2003; Yen et al. 2002; 
Zhadanov et al. 2006). In addition, some patients with optic neuropathy, mostly sporadic and of clinically unknown cause, were found to have mtDNA mutations known to associate with LHON (Chan et al. 1996; Guo et al. 2000; Howell et al. 1992; Kim et al. 2003; Obermaier-Kusser et al. 1994; Sartore et al. 1995).

MtDNA mutations in Chinese patients with LHON have been reported, but most of them were only involved in limited number of cases (Guo et al. 2000; Pang and Lam 2002; Qian et al. 2005; Yen et al. 2002). Here, we report the molecular epidemiological analysis of the three most popular mtDNA mutations in 903 families with optic neuropathy. mtDNA mutations at nt11778, nt14484 and nt3460 have been identified in 346 families.

\section{Methods}

Families and clinical data

From July 1997 to August 2005, 903 Chinese probands suspected of having LHON or optic neuropathy of unknown cause were referred to us from the Eye Hospital, Zhongshan Ophthalmic Center, Guangzhou, China. Both male and female probands were collected. Family history was taken, with drawing of pedigrees. Ocular examination was performed by ophthalmologists. Special examinations, including X-rays, computed tomography (CT) scan, B-scan, visual field, and visual electrophysiology, were conducted to exclude other ocular or systemic diseases whenever necessary. Participating criteria of a proband in this study were basically the same as previously suggested (Man et al.
2003): (1) a proband with subacute visual reduction; (2) clinical presence of optic neuropathy; (3) optic neuropathy with known cause excluded. Informed consent conforming to the tenets of the Declaration of Helsinki and following the Guidance of Sample Collection of Human Genetic Diseases (863-Plan) by the Ministry of Public Health of China was obtained from the participating individuals or their guardians prior to the study.

\section{Mutation detection}

MtDNA was prepared from peripheral venous blood. Five pairs of primers encompassing mtDNA (AC_000021) nt11778, nt14484, and nt3460, respectively, were designed to amplify the mtDNA fragments harboring the three common mutations related to LHON. DNA fragments harboring G11778A or G3460A mutation were analyzed by allele-specific amplification (ASA, or mutation-specific priming) and single-strand conformational polymorphism (SSCP) analysis (Table 1). The T14484C mutation was detected by digestion with restriction endonuclease Bcc I as well as SSCP. From time to time, selected samples with possible mutations were further analyzed by direct sequencing. Any sample with abnormal migrational patterns other than standard normal or mutant sequence on SSCP analysis was further identified by DNA sequencing.

Allele-specific amplification (ASA)

Two common primary mutations for LHON at mtDNA, i.e., G11778A and G3460A, were amplified by duplex polymerase chain reaction (PCR) using

Table 1 Sequence and location of primers as well as methods used for mutation detection

\begin{tabular}{|c|c|c|c|c|}
\hline \multirow[t]{2}{*}{ Mutation } & \multirow[t]{2}{*}{ Methods } & \multirow[t]{2}{*}{ Primers (5'-3') (nucleotide position in mtDNA genome) } & \multicolumn{2}{|c|}{ Product length (bp) } \\
\hline & & & Normal & Mutant \\
\hline \multirow[t]{4}{*}{ G11778A } & ASA & F: TACGAACGCACTCACAcTCa (11759-11778) & 498 & 498,222 \\
\hline & & R: GGAGTATAGGGCTGTGACTA (11980-11961) & & \\
\hline & SSCP & F: AGCCCTCGTAGTAACAGCCA (11641-11660) & 340 & 340 \\
\hline & & R: GGAGTATAGGGCTGTGACTA (11980-11961) & & \\
\hline \multirow[t]{4}{*}{ G3460A } & $\mathrm{ASA}^{\mathrm{a}}$ & F: ACTACAACCCTTCGCTcACa (3441-3460) & 498 & 498,318 \\
\hline & & R: AGTAGAATGATGGCTAGGGTGAC (3758-3736) & & \\
\hline & SSCP & F: GGCATTCCTAATGCTTACCGA (3357-3377) & 307 & 307 \\
\hline & & R: TGATCAGAGGATTGAGTAAAC (3663-3643) & & \\
\hline \multirow[t]{2}{*}{$\mathrm{T} 14484 \mathrm{C}$} & RFLP and SSCP & F: AАCСCCACTAAAАCACTCAC (14387-14406) & 224 & 224 \\
\hline & & R: AAGCCTTCTCCTATTTATGG (14610-14591) & & \\
\hline
\end{tabular}

Primer sequences with lower case indicate modified nucleotides in order to specifically amplify the mutant sequence at nt11778 or nt3460

$A S A$ allele-specific amplification, SSCP single-strand conformational polymorphism, RFLP restriction fragment length polymorphism, $F$ forward, $R$ reverse

${ }^{\mathrm{a}}$ Multiplex polymerase chain reaction (PCR): this pair of primers mixed with the primers for ASA detection of G11778A 
mutation-specific primers (Table 1), as previously reported (Norby 1993; Norby et al. 1991).

Single-Strand Conformational Polymorphism (SSCP) analysis

Variations in the amplicons of mtDNA fragments were screened using SSCP analysis (Orita et al. 1989). Electrophoretic band patterns from standard mutations identified by sequencing were used as positive reference.

Restriction fragment length polymorphism (RFLP) of PCR products

DNA fragments harboring mtDNA T14484C mutation were amplified by using a pair of primers (Table 1). PCR was conducted at $94^{\circ} \mathrm{C}$ for $8 \mathrm{~min}$, followed by five-cycle amplification at $94^{\circ} \mathrm{C} 30 \mathrm{~s}, 58^{\circ} \mathrm{C} 30 \mathrm{~s}$, and $72^{\circ} \mathrm{C} 30 \mathrm{~s}$; then 35 cycles at $94^{\circ} \mathrm{C} 30 \mathrm{~s}, 56^{\circ} \mathrm{C} 30 \mathrm{~s}, 72^{\circ} \mathrm{C}$ $30 \mathrm{~s}$; and finally at $72^{\circ} \mathrm{C}$ for $5 \mathrm{~min}$. Amplicons $(224 \mathrm{bp}$, $20 \mu \mathrm{l})$ were digested with 1 unit of Bcc I at $37^{\circ} \mathrm{C}$ for $3-$ $4 \mathrm{~h}$ and then separated on $8 \%$ nondenaturing polyacrylamide gel. The results were visualized by silver staining.

Sequence analysis

DNA fragments harboring mtDNA nt11778, nt14484, and nt 3460 , respectively, were amplified separately by using three pairs of primers for SSCP analysis. The amplicons were sequenced with the ABI BigDye Terminator cycle sequencing kit v3.1 (Applied Biosystems, Foster City, CA, USA) according to the manufacturer's recommendations using an ABI 377 or ABI 3100 sequencer. Sequencing results from patients as well as mtDNA consensus sequences from the National Center for Biotechnology Information (NCBI) human genome database (AC_000021) were imported into the SeqManII program of the Lasergene package (DNASTAR) and aligned to identify variations.

\section{Results and discussion}

Both of the G11778A and G3460A mutations yielded significant different band patterns on SSCP analysis and ASA so that they were successfully detected by both SSCP (Fig. 1a) and ASA (Fig. 1b) analyses. The T14484C mutation was successfully detected by Bcc I restriction digestion (Fig. 1c). The T14484C mutation could also be detected by SSCP (Fig. 1a), but sometime the SSCP analysis had to be repeated, as the band patterns for this mutation varied from time to time. Each individual with T14484C or G3460A mutation was further identified by sequencing (data not shown). Only randomly selected samples with G11778A mutation, already detected by SSCP and ASA analysis, were further identified by sequencing. a

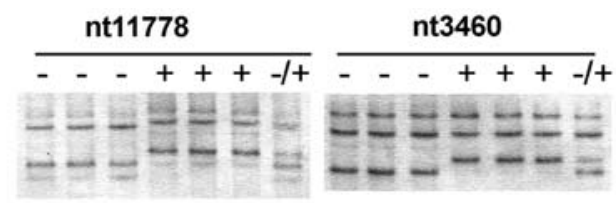

b
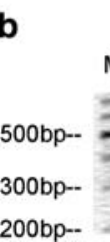

nt11778

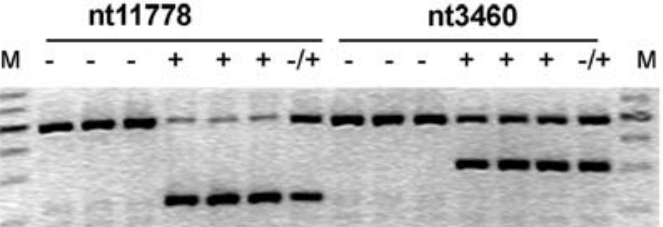

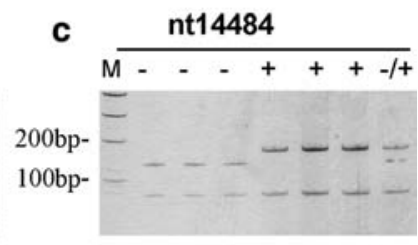

Fig. 1 Detection of three common mutations for Leber hereditary optic neuropathy (LHON). a Single-strand conformational polymorphism (SSCP) analysis of polymerase chain reaction (PCR) products harboring mitochondrial DNA (mtDNA) mutations at nt11778, nt3460, and nt14484: - normal; + mutation; $-/+$ heteroplasmic mutation. b Allele-specific amplification (ASA) results on agarose gel: a specific 222-bp band was observed in samples with G11778A mutation, and a specific 318bp band was observed in samples with G3460A mutation. In addition, a nonspecific 498-bp band was also observed, which served as an excellent internal control. The two pairs of primers for ASA detection of G11778A and G3460A were always worked together in amplification (duplex PCR). c Bcc I cut of mtDNA fragments with T14484C mutation on polyacrylamide gel. The mutation erases one of the two Bcc I sites in the amplicons. Bcc I digestion of the 224-bp normal fragments resulted in 121-, 76-, and 27-bp fragments. There would be only two fragments of 148 and $76 \mathrm{bp}$ in length for amplicons with T14484C mutation after Bcc I digestion. The 27-bp fragments, with length similar to primers, are usually not visible in routine silver staining of the polyacrylamide gels. The size standards in $\mathbf{b}$ and $\mathbf{c}$ were 100-bp ladders 
Table 2 Mutation detected in the mitochondrial DNA (mtDNA)

\begin{tabular}{|c|c|c|c|c|c|c|c|c|c|c|c|c|}
\hline \multirow[t]{2}{*}{ Mutation position } & \multicolumn{5}{|c|}{ Probands analyzed } & \multicolumn{5}{|c|}{ Mutation detected } & \multicolumn{2}{|l|}{ Mutation types } \\
\hline & Total & Male & Female & Familial & Sporadic & Total & Male & Female & Familial & Sporadic & Homoplasmic & Heteroplasmic \\
\hline Total & 903 & 640 & 263 & 128 & 775 & 346 & 284 & 62 & 120 & 226 & 340 & 6 \\
\hline G11778A & 903 & 640 & 263 & 128 & 775 & 312 & 257 & 55 & 108 & 204 & 311 & 1 \\
\hline T14484C & 903 & 640 & 263 & 128 & 775 & 30 & 24 & 6 & 11 & 19 & 26 & 4 \\
\hline G3460A & 903 & 640 & 263 & 128 & 775 & 4 & 3 & 1 & 1 & 3 & 3 & 1 \\
\hline
\end{tabular}

Of the 903 probands suspected with LHON, 640 $(70.9 \%)$ were male and $263(29.1 \%)$ were female; 128 $(14.2 \%)$ had a family history (Table 2$)$. Three hundred and forty-six probands $(346 / 903,38.3 \%)$ had one of the three common mutations, i.e., G11778A, T14484C, or G3460A. None of the samples had more than one of these three mutations. Mutations at nt11778, nt14484, and nt3460 were detected in 312 (90.2\%), 30 (8.7\%), and four $(1.1 \%)$ probands, respectively. This further confirmed the previous spectrum identified in the EastAsian population (Chuenkongkaew et al. 2001; Kim et al. 2003; Mashima et al. 1998; Yamada et al. 2001; Yen et al. 2002). Mutations in 340 probands were homoplasmic, and those in only six probands were heteroplasmic, which included one case at G11778A, four cases at $\mathrm{T} 14484 \mathrm{C}$, and one case at G3460A. Heteroplasmic mutation is comparatively rare in the Chinese compared with the white population (Man et al. 2003; Yen et al. 1999). Of the 346 probands with one of the three mutations, $120(34.7 \%)$ had a family history and $226(65.3 \%)$ were sporadic.

There were three mutations detected in $93.8 \%$ (120/ 128 ) probands with a family history of optic neuropathy. Supposing all these familial cases were suffering from LHON (actually, they might not), at least $93.8 \%$ of LHON resulted from these three common mutations in mtDNA. This result confirmed previous findings that other primary mutations related with LHON is rare (Mackey et al. 1996; Taylor et al. 2003). It is quite interesting that the three primary mutations were identified in 226 out of $775(29.2 \%)$ probands with sporadic optic neuropathy, mostly of unknown cause. Previously, analysis of mtDNA mutations in sporadic cases with optic neuropathy has been very limited, and mtDNA mutations were only detected in a small number of sporadic cases. The primary mutations at mtDNA in sporadic cases were rarely detected in the Caucasian population (Chan et al. 1996; Man et al. 2003; Marotta et al. 2004) but were more frequently reported in Asians (Kim et al. 2003; Mashima et al. 1998; Yamada et al. 2001). Yamada and Mashima identified these three mutations in 42 Japanese with sporadic optic neuropathy, and Kim detected such mutations in 41 Korean with sporadic optic neuropathy
(Kim et al. 2003; Mashima et al. 1998; Yamada et al. 2001). The exact rate of these mutations in sporadic optic neuropathy has not been well established, except that Chan reported that $11 \%$ of individuals with sporadic optic neuropathy of uncertain etiology were suffering from LHON (Chan et al. 1996). Our results indicate that the majority $(226 / 346,65.3 \%)$ of all LHON cases in Chinese are sporadic, which is much higher than $8 \%$ of all LHON cases in Australia (Chan et al. 1996). Therefore, routine screening of mtDNA mutations is highly recommended in Chinese patients with unexplained optic neuropathy.

Of the 346 probands with one of the three mtDNA mutations, $284(82.1 \%)$ were male and $62(17.9 \%)$ were female, with a male-to-female ratio of 4.6:1 (Table 3). Male probands had a higher risk of having these mutations $(284 / 640,44.4 \%)$ than were female probands $(62 / 263,23.6 \%)$. However, this may not really reflect the true ratio in the Chinese population, as males may have more opportunity to come to our hospital than females due to economic and social reasons. In addition, a male proband, especially with a family history, may be more likely to be referred to our department for mtDNA evaluation. Therefore, the male-to-female ratio of LHON was calculated again based on all affected individuals in the 120 families with mtDNA mutations (Table 3). There were 331 affected members in the 120 families with a male-to-female ratio of 2.2:1, which is significantly lower than the ratio $4.6: 1$ for probands with mtDNA mutations. The male-to-female ratio is similar between different mutations. Whether calculated based on probands or affected family members, the male-to-female ratio for LHON in Chi-

Table 3 Affected ratio of male to female

\begin{tabular}{llll}
\hline & All probands & $\begin{array}{l}\text { Familial } \\
\text { probands }\end{array}$ & $\begin{array}{l}\text { Family } \\
\text { members }\end{array}$ \\
\hline G11778A & $4.7: 1(257: 55)$ & $4.1: 1(87: 21)$ & $2.2: 1(198: 92)$ \\
T14484C & $4.0: 1(24: 6)$ & $4.5: 1(9: 2)$ & $2.3: 1(27: 12)$ \\
G3460A & $(3: 1)$ & $(1: 0)$ & $(1: 1)$ \\
All mutations & $4.6: 1(284: 62)$ & $4.0: 1(97: 23)$ & $2.2: 1(226: 105)$
\end{tabular}

Numbers in brackets represent the actual number of male-tofemale cases 
Table 4 Age at onset for Leber hereditary optic neuropathy (LHON) probands with mitochondrial DNA (mtDNA) primary mutations

\begin{tabular}{llrlccc}
\hline $\begin{array}{l}\text { Age } \\
\text { (years) }\end{array}$ & $\begin{array}{l}\text { All } \\
\text { probands }\end{array}$ & Male & Female & G11778A & T14484C $\begin{array}{l}\text { With } \\
\text { family } \\
\text { history }\end{array}$ \\
\hline $\begin{array}{c}\text { Total } \\
\text { cases }\end{array}$ & 346 & 284 & 62 & 312 & 30 & 120 \\
$<10$ & 10 & 10 & 0 & 10 & 0 & 4 \\
$10-19$ & 230 & 189 & 41 & 205 & 21 & 79 \\
$20-29$ & 77 & 60 & 16 & 70 & 7 & 31 \\
$30-39$ & 22 & 18 & 4 & 20 & 2 & 5 \\
$40-49$ & 7 & 6 & 1 & 7 & 0 & 1 \\
Average & 18.5 & 18.5 & 18.5 & 18.6 & 18.3 & 18.6 \\
age & & & & & & \\
\hline
\end{tabular}

Only four probands had G3460A mutation so they were not listed separately

nese is much lower than that in Japanese (8:1) (Mashima et al. 1998) or Australians (12.4:1) (Marotta et al. 2004).

Average age at onset of LHON was 18.5 years, ranging from 4.5 to 47 years old, with $66.5 \%$ between 10 and 19 years and $88.7 \%$ between 10 and 29 years (Table 4).

Acknowledgment The authors thank all patients and family members for their participation. This study was supported in part by the National 863 Plan of China (Z19-01-04-02 to QZ), National Natural Science Foundation (30572006 to QZ), and Foundation from Ministry of Education of China (20050558073 to QZ).

\section{References}

Chan C, Mackey DA, Byrne E (1996) Sporadic Leber hereditary optic neuropathy in Australia and New Zealand. Aust N Z J Ophthalmol 24:7-14

Chuenkongkaew WL, Lertrit P, Poonyathalang A, Sura T, Ruangvaravate N, Atchaneeyasakul L, Suphavilai R (2001) Leber's hereditary optic neuropathy in Thailand. Jpn J Ophthalmol 45:665-668

Guo L, Jia X, Xiao X, Guo X, Yu Q, Li M, Li S, Zhang Q (2000) Screening for mt-DNA mutations in optic neuritis of unknown cause. Chin Med J (Engl) 113:640-642

Howell N, McCullough D, Bodis-Wollner I (1992) Molecular genetic analysis of a sporadic case of Leber hereditary optic neuropathy. Am J Hum Genet 50:443-446

Huoponen K, Vilkki J, Aula P, Nikoskelainen EK, Savontaus ML (1991) A new mtDNA mutation associated with Leber hereditary optic neuroretinopathy. Am J Hum Genet 48:1147-1153

Johns DR, Neufeld MJ, Park RD (1992) An ND-6 mitochondrial DNA mutation associated with Leber hereditary optic neuropathy. Biochem Biophys Res Commun 187:1551-1157

Kim JY, Hwang JM, Chang BL, Park SS (2003) Spectrum of the mitochondrial DNA mutations of Leber's hereditary optic neuropathy in Koreans. J Neurol 250:278-281
Mackey DA, Oostra RJ, Rosenberg T, Nikoskelainen E, BronteStewart J, Poulton J, Harding AE, Govan G, Bolhuis PA, Norby S (1996) Primary pathogenic mtDNA mutations in multigeneration pedigrees with Leber hereditary optic neuropathy. Am J Hum Genet 59:481-485

Man PY, Griffiths PG, Brown DT, Howell N, Turnbull DM, Chinnery PF (2003) The epidemiology of Leber hereditary optic neuropathy in the North East of England. Am J Hum Genet 72:333-339

Marotta R, Chin J, Quigley A, Katsabanis S, Kapsa R, Byrne E, Collins S (2004) Diagnostic screening of mitochondrial DNA mutations in Australian adults 1990-2001. Intern Med J 34:10-19

Mashima Y, Yamada K, Wakakura M, Kigasawa K, Kudoh J, Shimizu N, Oguchi Y (1998) Spectrum of pathogenic mitochondrial DNA mutations and clinical features in Japanese families with Leber's hereditary optic neuropathy. Curr Eye Res 17:403-408

Nishioka T, Tasaki M, Soemantri A, Dyat M, Susanto JC, Tamam M, Sudarmanto B, Ishida T (2003) Leber's hereditary optic neuropathy with 14484 mutation in Central Java, Indonesia. J Hum Genet 48:385-389

Norby S (1993) Screening for the two most frequent mutations in Leber's hereditary optic neuropathy by duplex PCR based on allele-specific amplification. Hum Mutat 2:309-313

Norby S, Lestienne P, Nelson I, Rosenberg T (1991) Mutation detection in Leber's hereditary optic neuropathy by PCR with allele-specific priming. Biochem Biophys Res Commun 175:631-636

Obermaier-Kusser B, Lorenz B, Schubring S, Paprotta A, Zerres K, Meitinger T, Meire F, Cochaux P, Blankenagel A, Kommerell $\mathrm{G}$ et al (1994) Features of mtDNA mutation patterns in European pedigrees and sporadic cases with Leber hereditary optic neuropathy. Am J Hum Genet 55:1063-1066

Orita M, Suzuki Y, Sekiya T, Hayashi K (1989) Rapid and sensitive detection of point mutations and DNA polymorphisms using the polymerase chain reaction. Genomics 5:874-879

Pang CP, Lam DS (2002) Differential occurrence of mutations causative of eye diseases in the Chinese population. Hum Mutat 19:189-208

Phasukkijwatana N, Chuenkongkaew WL, Suphavilai R, Suktitipat B, Pingsuthiwong S, Ruangvaravate N, Atchaneeyasakul LO, Warrasak S, Poonyathalang A, Sura T, Lertrit P (2006) The unique characteristics of Thai Leber hereditary optic neuropathy: analysis of 30 G11778A pedigrees. J Hum Genet 51:298-304

Qian Y, Zhou X, Hu Y, Tong Y, Li R, Lu F, Yang H, Mo JQ, Qu J, Guan MX (2005) Clinical evaluation and mitochondrial DNA sequence analysis in three Chinese families with Leber's hereditary optic neuropathy. Biochem Biophys Res Commun 332:614-621

Sartore M, Grasso M, Piccolo G, Fasani R, Bergamaschi R, Malaspina A, Ceroni M, Kobayashi M, Semeraro A, Arbustini E et al (1995) Leber's hereditary optic neuropathy (LHON)-related mitochondrial DNA sequence changes in Italian patients presenting with sporadic bilateral optic neuritis. Biochem Mol Med 56:45-51

Shanske S, Wong LJ (2004) Molecular analysis for mitochondrial DNA disorders. Mitochondrion 4:403-415

Taylor RW, Jobling MS, Turnbull DM, Chinnery PF (2003) Frequency of rare mitochondrial DNA mutations in patients with suspected Leber's hereditary optic neuropathy. J Med Genet 40:e85

Votruba M (2004) Molecular genetic basis of primary inherited optic neuropathies. Eye 18:1126-1132 
Wallace DC, Singh G, Lott MT, Hodge JA, Schurr TG, Lezza AM, Elsas LJ II, Nikoskelainen EK (1988) Mitochondrial DNA mutation associated with Leber's hereditary optic neuropathy. Science 242:1427-1430

Yamada K, Mashima Y, Hiida Y, Oguchi Y (2001) DNA diagnosis of Leber's hereditary optic neuropathy performed at Keio University Hospital. Nippon Ganka Gakkai Zasshi 105:608-613

Yen MY, Lee HC, Wang AG, Chang WL, Liu JH, Wei YH (1999) Exclusive homoplasmic 11778 mutation in mitochondrial DNA of Chinese patients with Leber's hereditary optic neuropathy. Jpn J Ophthalmol 43:196-200
Yen MY, Wang AG, Chang WL, Hsu WM, Liu JH, Wei YH (2002) Leber's hereditary optic neuropathy—the spectrum of mitochondrial DNA mutations in Chinese patients. Jpn J Ophthalmol 46:45-51

Zhadanov SI, Atamanov VV, Zhadanov NI, Schurr TG (2006) De novo COX2 mutation in a LHON family of Caucasian origin: implication for the role of mtDNA polymorphism in human pathology. J Hum Genet 51:161-170 